\title{
SAE Battery
}

National Cancer Institute

\section{Source}

National Cancer Institute. SAE Battery. NCI Thesaurus. Code C154702.

A series of evaluations designed to learn whether cancer treatment changes emotions, attention span, or behavior, or the way the brain processes and filters information. 